\title{
EDUKASI E-COMMERCE PADA PELAKU USAHA MIKRO, KECIL DAN MENENGAH (UMKM) DI KOTA PALEMBANG
}

\author{
Budi Setiawan1) \\ 1), Program Studi Manajemen Universitas Indo Global Mandiri \\ Jalan Jenderal Sudirman No. 629 Palembang Kode pos 30129 \\ Email : $\underline{\text { budi.setiawan@uigm.ac.id }}^{1)}$
}

\begin{abstract}
ABSTRAK
Teknologi sudah menjadi bagian terintegrasi dari kehidupan manusia. Perkembangan teknologi tidak hanya merubah model bisnis yang bergerak di bidangnya, tapi juga sudah merambah ke berbagai bidang, termasuk Usaha Mikro, Kecil dan Menengah (UMKM). Keberadaan UMKM di Indonesia dipercayai mampu memberikan kontribusi yang sangat besar bagi perekonomian Indonesia. Oleh karena itu, agar para pelaku UMKM terus dapat bertahan di dunia dengan perubahaan teknologi sangat cepat, maka pelaku UMKM harus terus belajar dan siap untuk merubah model bisnis mengikuti perkembangan zaman. Salah satu perubahan tersebut dengan mendigitalisasi produk yang mereka jual. Edukasi bagi UMKM di kota Palembang terkait bagaimana mengkoneksikan produk mereka secara digital penting untuk dilakukan agar bisnis UMKM tidak hanya bertahan di tengah persaingan tapi juga bisa tumbuh dan berkembang ke skala yang lebih besar.
\end{abstract}

Kata kunci : E-Commerse, Digitalisasi, UMKM

\section{PENDAHULUAN}

Usaha Mikro, Kecil dan Menengah (UMKM) memiliki peranan penting bagi perekonomian di Indonesia. Menurut laporan Bank Indonesia menyebutkan bahwa UMKM berkontribusi sebesar 99,99\% dari total keseluruhan pelaku usaha di Indonesia atau sebanyak 56,54 juta unit. Pelaku UMKM, khususnya yang bergerak di produk ekonomi kreatif menyumbang Produk Domestik Bruto (PDB) sebesar Rp.852 triliun dan mampu menyerap tenaga kerja sebanyak 15 juta orang. Selain itu, keberadaan UMKM juga dipercaya tahan terhadap goncangan krisis ekonomi.

Perkembangan UMKM di Indonesia juga tak lepas dari peran aktif sektor perbankan dalam memberikan akses perkreditan. Hal ini dibuktikan dengan Peraturan Bank Indonesia (PBI) No. 14/22/PBI/2012 tanggal 21 Desember 2012 tentang Pemberian Kredit oleh Bank Umum dan Bantuan Teknis dalam Rangka Pengembangan UMKM. PBI mengamanatkan kepada bank untuk memberikan porsi kredit sekurang-kurangnya 5\% kepada UMKM terhadap total kredit yang dikucurkan perbankan. Data yang dilaporkan Bank Indonesia mencatat bahwa nilai kredit yang disalurkan pada UMKM mencapai Rp.900 triliun pada tahun 2016 atau meningkat sebesar 128\% dibandingkan tahun 2010 sebesar Rp.394 triliun.

Besarnya kontribusi UMKM terhadap perekonomian Indonesia mendorong semua kalangan memberikan perhatian khusus terhadap perkembangan UMKM. Perhatian tersebut mencakup kesiapan UMKM dalam menghadapi persaingan di Era Digital. Kajian yang dilakukan oleh Bank Dunia terkait UMKM di Indonesia menyebutkan bahwa penggandaan tingkat akses dan keterlibatan UMKM secara digital dipredikasi mampu meningkatkan pertumbuhan ekonomi sebesar $2 \%$. Tambahan pertumbuhan ekonomi dari sektor UMKM ini diyakini mampu mendorong target pertumbuhan ekonomi Indonesia menjadi 7\%, yang merupakan salah satu syarat untuk menjadikan Indonesia sebagai negara berpenghasilan menengah pada tahun 2025.

Peran pelaku UMKM di Indonesia harus terus ditingkatkan tidak hanya dari segi kuantitas tapi juga kualitas, termasuk terkoneksi dengan internet. Menurut penelitian Namani (2009) tentang Small Places can Change the World menyebutkan bahwa terknologi informasi, terutama internet memiliki dampak yang signifikan terhadap operasional UMKM yang disinyalir menjadi faktor utama dari perkembangan pelaku UMKM. UMKM yang terkoneksi dengan internet dianggap memiliki interaksi, fleksibilitas dan kemudahan transaksi dibandingkan UMKM yang masih konvensional atau belum terhubung dengan internet. 
Perhatian terhadap UMKM tersebut juga dilakukan oleh beberapa pihak di kota Palembang. Pendataan yang dilakukan oleh Badan Pusat Statistik (BPS) kota Palembang menyebutkan bahwa pelaku UMKM di kota Palembang mencapai 400 ribu pelaku usaha, angka ini tumbuh sebesar $100 \%$ dibandingkan pelaku UMKM di tahun 2006 sebanyak 200 ribu UMKM. Pelatihan dan pendampingan UMKM kota Palembang agar bisa terkoneksi dengan dunia digital sangat penting dilakukan guna mengoptimalkan perkembangan bisnis yang pada akhirnya mampu mendorong menciptakan lapangan kerja baru serta berkontribusi terhadap kegiatan ekonomi di kota Palembang.

\subsection{Tujuan Pengabdian}

Tujuan dari kegiatan pengabdian kepada masyarakat ini adalah :

1. Meningkatkanpengetahuantentang pentingnya dunia digital bagi perkembangan bisnis UMKM

2. Mendorong pelaku UMKM agar mendigitalisasi produk yang mereka tawarkan

3. Memfasilitasi pelaku UMKM untuk membuat mini website yang disediakan oleh Google yaitu Google My Business

4. Memperkenalkan cara pemasaran baru bagi pelaku UMKM melalui marketplace seperti Bukalapak,Tokopedia dan lain-lain.

\subsection{Manfaat Pengabdian}

Adapun manfaat yang akandiperoleh pelaku UMKM kota Palembang antara lain :

1. Menambahpengetahuanterkait potensi bisnis yang bisa diraih dengan cara mendigitalisasi UMKM

2. Mengajakpelaku UMKM mulai memasarkan produk mereka melalui marketplace lokal.

3. Mengembangkan jaringan bagi pelaku UMKM agar bisa melakukan kolaborasi bisnis yang saling menguntungkan.

\section{METODE PELAKSANAAN PENGABDIAN}

\subsection{Analisa dan Solusi Permasalahan}

Besarnya peran UMKM bagi Indonesia baik sebagai kontributor pertumbuhan ekonomi maupun penciptaan lapangan kerja di Indonesia, mendorong semua pihak untuk terlibat dalam hal proses pengembangan UMKM di Indonesia. Proses pengembangan UMKM di Indonesia dirasa sangat perlu untuk dilakukan mengingat masih rendahnya partisipasi UMKM yang terhubung dengan internet. Menurut laporan Deloitte Access Economics tentang UKM Pemicu Kemajuan Indonesia menerangkan bahwa tingkat penggunaan teknologi digital pelaku UMKM masih sangat rendah.

Hal ini diungkapkan bahwa sebanyak 36\% UMKM belum terkoneksi dengan internet (offline), $37 \%$ UMKM hanya menggunakan internet untuk keperluan yang sangat mendasar (basic online) seperti menggunakan internet hanya untuk keperluan media sosial, 18\% UMKM sudah pada level menengah (intermediate online) artinya pelaku usaha tidak hanya terlibat di media sosial tetapi juga sudah bisa mengintegrasikan sosial media dengan pelanggan produk mereka. Lebih jauh, hanya 9\% UMKM yang sudah memaksimalkan peran internet untuk mengembangkan usaha mereka (advanced online).

Berdasarknan penjelasan di atas, sekaligus untuk mendorong pemerintah guna mendigitalilasi pelaku UMKM di Indonesia, maka pengabdian masyarakat dengan tema Edukasi E-Commerce pada Pelaku UMKM di Kota Palembang perlu untuk dilakukan. Penulis berharap bahwa edukasi ini mampu memberi informasi tentang pentingnya pelaku UMKM untuk mulai terkoneksi dengan internet, yang pada akhirnya mampu mengoptimalkan bisnis mereka, menciptakan lapangan kerja yang lebih banyak serta memperkokoh pertumbuhan ekonomi Indonesia. Akhirnya melalui pengabdian ini, penulis berharap bisa menjadi bagian dari solusi atas rencana pemerintah untuk terus mengoptimalisasi peran UMKM bagi pertumbuhan ekonomi di Indonesia. 


\subsection{Tindak Lanjut dengan Pelaku UMKM}

Tindak lanjut setelah melakukan edukasi digitalisasi pelaku UMKM kota Palembang yaitu memastikan bahwa pelaku UMKM agar dapat memaksimalkan internet sebagai media untuk membantu mengembangkan bisnis mereka. Hal paling sederhana yang bisa dilakukan pelaku UMKM yaitu membuat website gratis melalui Google My Business. Maksimalisasi website sangat penting untuk memasarkan produk UMKM, selain itu mendaftarkan bisnis UMKM ke Google My Business juga mampu memberikan petunjuk arah bagi calon pelanggan ke lokasi tempat UMKM melakukan bisnis. Tidak hanya itu, pelaku UMKM juga bisa menerima ulasan yang diberikan oleh pelanggan atas produk yang kita tawarkan. Dengan cara seperti ini, secara tidak langsung pelaku UMKM bisa mengevaluasi bisnis mereka setiap saat dengan mengacu pada ulasan yang diberikan oleh pelanggan mereka.

\subsection{Persiapan Pelaksanaan Pengabdian}

Sebelum kegiatan pengabdian pada masyarakat dilakukan perlu adanya persiapan yang harus dilakukan terlebih dahulu seperti:

1. Melakukandiskusi dengan perwakilan Google di kota Palembang tentang tujuan dan target dilakukan acara edukasi digital bagi pelaku UMKM kota Palembang.

2. Menetapkan hari, tanggal kegiatan, tempat serta peralatan yang perlu dipersiapkan untuk pelaksanaan kegiatan pelatihan tersebut.Persiapan yang dilakukan untuk pelaksanaan kegiatan tersebut adalah menyediakan ruang pelatihan beserta peralatan pendukung seperti laptop, proyektor dan lain-lain. Kegiatan pengabdian dilakukan di Lord Caffe Palembang.

3. Mempersiapkan materi pelatihan dalam bentuk modul yang akan disampaikan kepada pelaku UMKM Palembang. Membuat akun Google Drive yang akan digunakan untuk menyimpan materi pelatihan yang nantinya bisa diakses oleh peserta pelatihan.

4. Memastikan bahwa peserta pelatihan bisa membuat akun di Google My Business dan mengerti tentang apa yang harus mereka lakukan untuk terus meng-update produk mereka di Google My Business.

5. Setelah persiapan selesai, ditetapkan waktu pelatihan edukasi E-commerse bagi pelaku UMKM Palembang pada tanggal21 April 2018 mulai pukul 09:00 hingga 17:00 yang bertempat di Lord Caffe Palembang.

\subsection{Pelaksanaan Pengabdian}

Pelaksanan pengabdian dimulai dengan memberikan informasi terkait manfaat digitalisasi bagi pelaku UMKM. Pada sesi ini, diberikan beberapa contoh para pelaku UMKM yang sudah mendigitalisasi bisnis mereka, serta merasakan dampak positif dari proses tersebut. Tahapan selanjutnya yaitu pelatihan membuat akun website di Google My Business, termasuk bagaimana memaksimalkan fitur dan konten yang ada Google My Business untuk bisa memaksimalkan pemasaran produk pelaku UMKM. Urutan pada saat pelatihan yaitu pembukaan yang disampaikan oleh perwakilan Google dan dilanjutkan dengan penyampaian materi pada pelaku UMKMkota Palembang dan diakhiri dengan diskusi serta tanya jawab.

\begin{tabular}{|c|c|c|}
\hline Tanggal & Waktu & Materi \\
\hline 21 April 2018 & $09: 00-12: 00$ & Panduan Dunia Digital \\
\hline 21 April 2018 & $13: 30-17: 00$ & Listing di Google My Business \\
\hline
\end{tabular}




\section{HASIL DAN PEMBAHASAN}

\subsection{HasilPengabdian}

Berdasarkan wawancara, tanya jawab dan pengamatan langsung selama kegiatan edukasi ecommerce pelaku UMKM di kota Palembang, kegiatan pengabdian pada masyarakat ini memberikan hasil sebagai berikut :

- Memberikanpemahamandaninformasibarubagi para pelaku UMKM di kota Palembang tentangpentingnyamenghubungkanbisnismerekadengandunia digital.

- Para pesertamembuat mini website melaluiplatfom gratis yang sudah disediakan oleh Google yaitu Aplikasi Google My Business. Selain itu peserta juga diberi informasi seputar bagaimana membuat website yang efektif sesuai dengan karakteristik perusahaan dan target konsumen yang ingin dicapai.

\subsection{Pembahasan Pengabdian}

Selama kegitan pengabdian berlangsung, ada beberapa faktor pendukung terlaksanannya pengabdian kepada masyarakat ini antara lain banyaknya pelaku UMKM di kota Palembang yang berminat untuk mendigitalisasi bisnis mereka. Hal ini terlihat dari antusiasme jumlah peserta yang mencapai 120 orang. Meskipun jumlah peserta cukup banyak tetapi edukasi e-commerce pada pelaku UMKM kota Palembang tetap berjalan dengan lancar dan efektif. Acara ini sendiri di sponsori oleh Google Indonesia guna mengambangkan pelaku UMKM di Indonesia termasuk kota Palembang.

Faktor penghambat saat kegiatan berlangsung yaitu salah satu mix yang digunakan tidak berfungsi dengan baik sehingga sempat menggangu komunikasi peserta dan pembicara saat melakukan diskusi dan tanya jawab. Selain itu, jumlah peserta yang melebihi target juga menyebabkan beberapa peserta harus duduk di lokasi yang cukup jauh dari layar proyektor. Guna mengatasi faktor penghambat tersebut, penulis memberikan materi yang bisa di unduh oleh semua peserta workshop yang hadir.
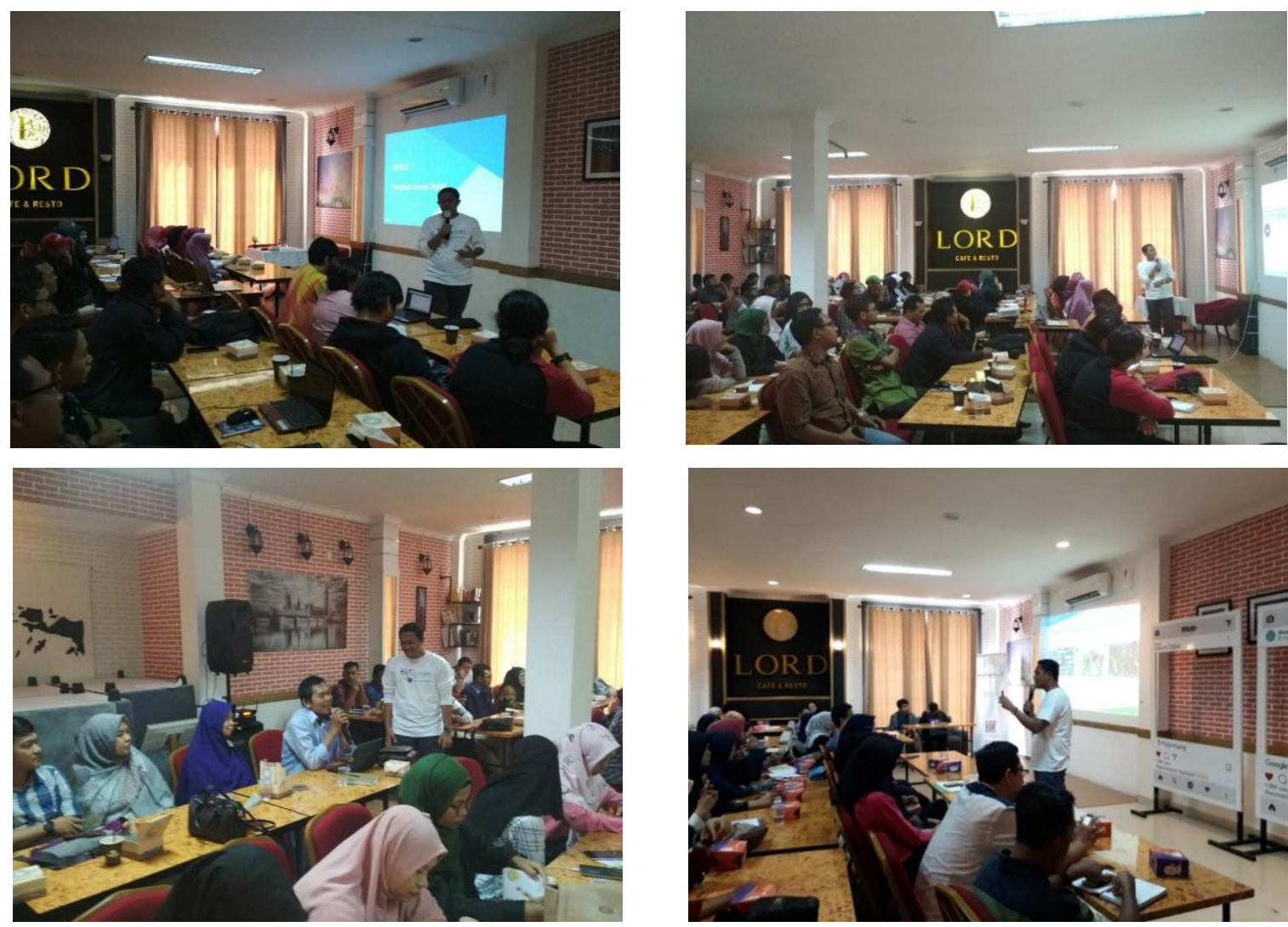

Gambar 1. Suasana Pelatihan 


\section{KESIMPULAN DAN SARAN}

\subsection{Kesimpulan Pengabdian}

Berdasarkan hasil pelaksanaan kegiatan pengabdian pada masyarakat yang telah dilakukan, dapat ditarik beberapa simpulan sebagai berikut :

1. Proses kegiatan pengabdian kepada masyarakat dengan tema edukasi e-commerce para pelaku UMKM di kota Palembang berjalan dengan lancar. Peserta yang hadir sebanyak 120 orang yang mewakili lebih dari 100 UMKM di kota Palembang.

2. Peserta yang hadir dan mengikuti workshop edukasi e-commerce ini juga sudah membuat mini website yang disediakan secara gratis melalui platfom Google My Business. Platform tersebut tidak hanya handal dalam media promosi tapi juga bisa menghubungkan pelaku UMKM dengan pelanggan mereka. Selain itu, Google My Business juga menyediakan kolomulasan (review) yang bisa digunakan oleh customer untukmemberikanfeedbackterkaitproduk yang ditawarkanolehpelaku UMKM di kota Palembang.

3. Saat proses edukasi berlangsung, penulis juga memberikan beberapa contoh pelaku UMKM yang mampu pengoptimalkan bisnis mereka setelah aktif menghubungkan usaha mereka dengan internet.

\subsection{Saran Pengabdian}

Adapun saran yangpenulisberikan dalamkegiatanpengabdianmasyarakattentang edukasi Ecommerce bagi pelaku UMKM Palembang antara lain :

1. Bagi pelaku UMKM hendaknya segera mengkoneksikan bisnis mereka ke dunia digital agar bisa mengoptimaklan proses promosi usaha yang pada akhirnya berdampak terhadap perkembangan usaha mereka.

2. Pemerintah, praktisi dan akademisi diharapkan berperan aktif untuk melakukan sosialisasi dan edukasi tentang pentingnya digitalisasi pelaku UMKM untuk mengoptimalkan perkembangan bisnis, menciptakan tenaga kerja yang pada akhirnya diharapkan mampu mendorong pertumbuhan ekonomi di Indonesia.

3. Penulis akan mendindaklanjuti pengabdian kepada masyarakat ini dengan cara melakukan kunjungan ke beberapa peserta pelaku UMKM yang hadir guna memastikan bahwa mereka sudah memahami bagaimana memaksimalkan peran internet untuk memaksimalkan bisnis mereka.

\section{DAFTAR PUSTAKA}

Bank Indonesia. (2015). Profil Bisnis Usaha Mikro, Kecil dan Menengah (UMKM). Lembaga Pengembangan Perbankan Indonesia.

Deloitte Access Economics. (2015). UKM Pemicu Kemajuan Indonesia. Instrumen Pertumbuhan Nusantara.

Namani, M.B. (2009). The Role of Information Technology in Small and Medium Sized Enterprises in Kosovo. Small Places Can Change the World. Fulbright Academy 2009 Conference. 